\title{
PELATIHAN ELEARNING DAN KONTEN PEMBELAJARAN DIGITAL UNTUK GURU PADA SEKOLAH DASAR ISLAM TERPADU ANAK SHOLEH MANDIRI BANJARMASIN
}

\author{
Yusri Ikhwani,. Silvia Ratna, Fathur Rahman, M. Rasyidan \\ Fakultas Teknologi Informasi, Universitas Islam Kalimantan \\ E-mail : yusri.ikhwani@gmail.com
}

\begin{abstract}
ABSTRAK
Seiring perkembangan zaman di era industri 4.0 perkembangan teknologi informasi berkembang sangat pesat dan teknologi informasi dapat memudahkan manusia untuk beraktifitas serta memudahkan dalam menyelesaikan suatu pekerjaan dengan cepat dan tepat, alah satu contohnya pemanfaatan penggunaaan elearning yang dapat dikembangkan dengan menggunakan platform yang open source. Sekolah Dasar Islam Terpadu Anak Sholeh Mandiri adalah salah satu sekolah swasta yang menerapkan pendekatan penyelenggaraan dengan memadukan pendidikan umum dan pendidikan agama menjadi satu jalinan kurikulum. Dengan pendekatan ini, semua mata pelajaran dan semua kegiatan sekolah tidak lepas dari bingkai ajaran dan pesan nilai Islam. Sebagai salah satu wujud dalam pengembangan ilmu pengetahuan dan teknologi maka pada kegiatan Pengabdian Masyarakat ini akan dilakukan suatu pelatihan Elearning Dan Konten Pembelajaran Digital Untuk Guru di Sekolah Dasar Islam Terpadu Anak Sholeh Mandiri Banjarmasin yang bertujuan untuk melatih mengembangkan elearning dan melakukan pendampingan kepada para guru agar mereka lebih mahir dan terampil dalam menggunakan elearning yang open source (gratis), selain itu sebagai salah satu media pendukung dalam pemamfaatan teknologi dalam proses belajar mengajar daring di Sekolah Dasar Islam Terpadu Anak Sholeh Mandiri. Hasil dari kegiatan Pengabdian Masyarakat dengan pelatihan elearning dan konten pembelajaran digital memberikan dampak positif terhadap guru dan sangat terbantukan karena pemberian materi, pengisian kehadiran siswa, pemberian tugas, pengumpulan tugas dan penilaian semua terkelola dalam satu aplikasi dan data bisa di unduh kembali apabila diperlukan
\end{abstract}

Kata kunci: elearning, konten, digital, terpadu

\begin{abstract}
As the times in the industrial era 4.0 development of information technology is developing very rapidly and information technology can enable people to indulge and ease of completing a pitch quickly and precisely, s ne of the example the utilization of the use of e - learning that can be developed with platform open source. The Sholeh Mandiri Children's Integrated Islamic Elementary School is a private school that applies an implementation approach by combining general education and religious education into one curriculum. With this approach, all subjects and all school activities cannot be separated from the framework of Islamic teachings and values. As a manifestation of the development of science and technology, this Community Service activity will carry out an Elearning and Digital Learning Content training for Teachers at the Sholeh Mandiri Children's Integrated Islamic Elementary School in Banjarmasin which aims to train to develop e - learning and provide assistance to teachers. so that they are more proficient and skilled in using open source (free) e-learning, as well as one of the supporting
\end{abstract}


media in the use of technology in the online teaching and learning process at the Sholeh Mandiri Children's Integrated Islamic Elementary School. The results of the activities of Community Service with training e - learning and learning content $d$ igital a positive impact on on teachers and are very helpful because providing material, filling student attendance, giving assignments, collecting assignments and assessing all are managed in one application and data can be downloaded again if needed.

Keywords: Elearning, Content, Digital

\section{PENDAHULUAN}

Seiring perkembangan zaman di era industri 4.0 perkembangan teknologi informasi berkembang sangat pesat dan teknologi informasi dapat memudahkan manusia untuk beraktifitas serta memudahkan dalam menyelesaikan suatu pekerjaan dengan cepat dan tepat, salah satu contohnya pemanfaatan penggunaaan elearning yang dapat dikembangkan dengan menggunakan platform yang open source (bisa dikembangkan dan dimanfaatkan secara gratis) serta dipadukan dengan keahlian dalam pembuatan konten pembelajaran digital. Pengertian E-learning adalah sebuah proses pembelajaran yang berbasis elektronik. Salah satu media yang digunakan adalah jaringan komputer. Dengan dikembangkannya di jaringan komputer memungkinkan untuk dikembangkan dalam bentuk berbasis web, sehingga kemudian dikembangkan ke jaringan komputer yang lebih luas yaitu internet. Penyajian e-learning berbasis web ini bisa menjadi lebih interaktif. Sistem e-learning ini tidak memiliki batasan akses, inilah yang memungkinkan pembelajaran bisa dilakukan lebih banyak waktu.

Saat ini terjadi masa pandemi covid-19 secara global yang mengakibatkan pembelajaran tatap muka tidak memungkinkan untuk dilaksanakan dan ini mengharuskan pembelajaran harus dilaksanakan secara daring. Begitu pula yang terjadi di Sekolah Dasar Islam Terpadu Anak Sholeh Mandiri guru yang mengajar masih belum memanfaatkan elearning dikarenakan belum memiliki kemampuan dalam memanajemen sistem elearning dan pemanfaatan konten-konten pembelajaran digital dimana materi pembelajaran masih sangat konvensional, selain itu cara memberi materi pembelajaran masih dalam bentuk komunikasi dengan orang tua siswa melalui media sosial.

Tujuan dari pelaksanaan kegiatan pengabdian ini adalah : 
1. Memberikan layanan kepada guru dalam bentuk pengembangan aplikasi elearning secara gratis (open source) serta ilmu pengetahuannya.

2. Memanfaatkan perkembangan ilmu pengetahuan bidang hardware dan software dalam proses pengembangan ilmu khususnya melakukan pelatihan menggunakan aplikasi elearning serta membuat konten pembelajaran digital bagi guru.

3. Memberikan pelatihan untuk guru di Sekolah Dasar Islam Terpadu Anak Sholeh Mandiri Banjarmasin agar dengan mudah menggunakan elearning sehingga konten belajar daring yang disampaikan urut dan sistematis.

\section{KHALAYAK SASARAN}

1. Memberikan pengetahuan tambahan kepada para guru sebagai peserta pelatihan elearning dan membuat konten pembelajaran digital di Sekolah Dasar Islam Terpadu Anak Sholeh Mandiri Banjarmasin yang ingin mengembangkan diri dalam disiplin ilmunya.

2. Memberikan pengetahuan dasar tentang elearning dan membuat konten pembelajaran digital untuk guru di Sekolah Dasar Islam Terpadu Anak Sholeh Mandiri Banjarmasin

3. Mencoba memanfaatkan perkembangan ilmu pengetahuan bidang hardware dan software dalam proses pengembangan ilmu khususnya tentang pelatihan Elearning dan Membuat Karya Konten Pembelajaran Digital bagi guru.

\section{METODE PELAKSANAAN \\ KEGIATAN}

Metode kegiatan yang diberikan dalam pelaksanaan pengabdian kepada masyarakat menggunakan beberapa metode yaitu meliputi Teori pengenalan elearning, pengenalan lembar kerja elearning serta praktek secara langsung Membuat Akun elearning dan Membuat Karya Konten Pembelajaran Digital menggunakan aplikasi. metode yang diberikan dengan beberapa materi yaitu:

1. Tutorial : Instruktur menjelaskan tentang pengertian dan manfaat elearning dan konten pembelajaran digital dengan menggunakan alat bantu LCD sehingga peserta dapat memahaminya 
2. Praktek : Setiap peserta melakukan praktek langsung berupa proses membuka, mengubah, menjalankan dan mengolah data menggunakan aplikasi

3. Tanya jawab : Peserta dapat langsung bertanya kepada tim pengabdian pada masyarakat yang mendampingi mereka selama kegiatan berlangsung.

\section{HASIL KEGIATAN DAN}

\section{PEMBAHASAN}

Hasil pelaksanaan kegiatan Pelatihan Elearning Dan Konten Pembelajaran Digital Untuk Guru Pada Sekolah Dasar Islam Terpadu Anak Sholeh Mandiri Banjarmasin perlu adanya evaluasi, salah satu metode yang digunakan adalah Kuisioner yang terdiri dari 2 aspek penilaian yaitu aspek manfaat dalam penerapan IPTEK dan aspek keterampilan pendidikan, dapat dilihat pada tabel berikut:

\begin{tabular}{cccc}
\hline No & Aspek & $\begin{array}{c}\text { Jumlah } \\
\text { Butir }\end{array}$ & $\begin{array}{c}\text { Butir } \\
\text { Soal }\end{array}$ \\
\hline \multirow{4}{*}{1} & Penerapan & & $1,2,3,4,5$ \\
& IPTEK & 14 & $, 6,7,8,9$, \\
& (Manfaat) & & $10,11,12$ \\
& & & $, 13,14$ \\
& Pemahaman & & $1,2,3,4,5$ \\
2 & dan & 10 & $, 6,7,8,9$, \\
& Keterampilan & 10 & \\
& (Pendidikan) & & \\
\hline
\end{tabular}

Kuisioner ini dilaksanakan dengan memanfaatkan google form dan ditanggapi oleh 27 repsonden (guru SD IT Anak Sholeh Mandiri), untuk mengetahui tanggapan responden terhadap sistem yang akan diimplementasikan yaitu dengan Angket Skala Likert yang umumnya digunakan untuk dalam riset berupa survei dan memberikan pertanyaan kepada responden dimana jawaban dari pertanyaan tersebut terdiri dari tingkatan yang dapat dipilih sebagai berikut:

\begin{tabular}{lc}
\hline Jawaban & Bobot \\
\hline Sangat Setuju (SS) & 5 \\
Setuju (S) & 4 \\
Ragu-ragu (RR) & 3 \\
Tidak Setuju (TS) & 2 \\
Sangat Tidak Setuju & 1 \\
(STS) & \\
\hline
\end{tabular}

Hasil kuisioner yang telah dijawab oleh 27 responden bahwa setelah mereka menggunakan aplikasi Edmodo berdasarkan aspek manfaat penerapan IPTEK maka menghasilkan nilai rata-rata 4,8 artinya Sangat Setuju (SS). Sedangkan dari aspek pemahaman dan keterampilan (Pendidikan) menghasilkan nilai rata-rata 4,9 artinya Sangat Setuju (SS). 


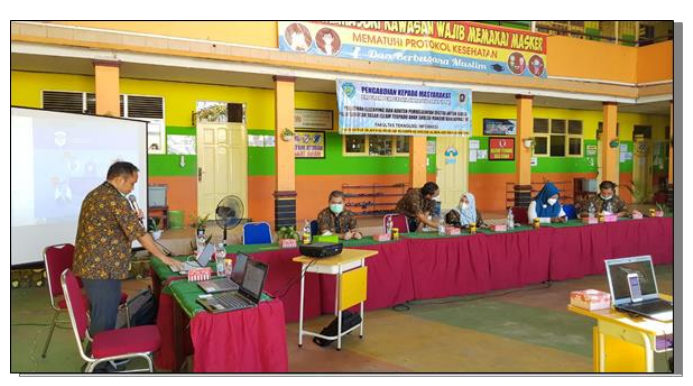

Gambar 1. Tim Pengabdian

memberikan materi pelatihan

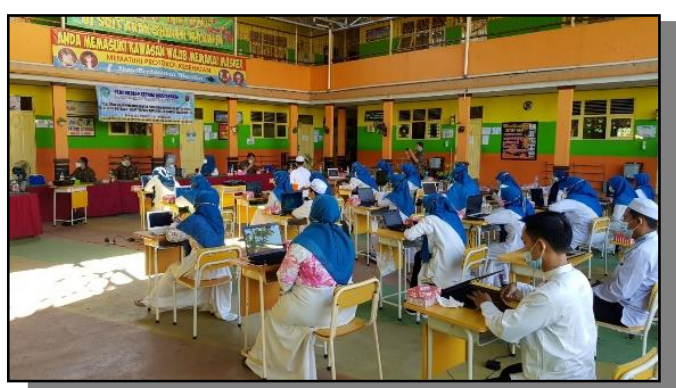

Gambar 2. Peserta mengikuti pelaksanaan pengabdian

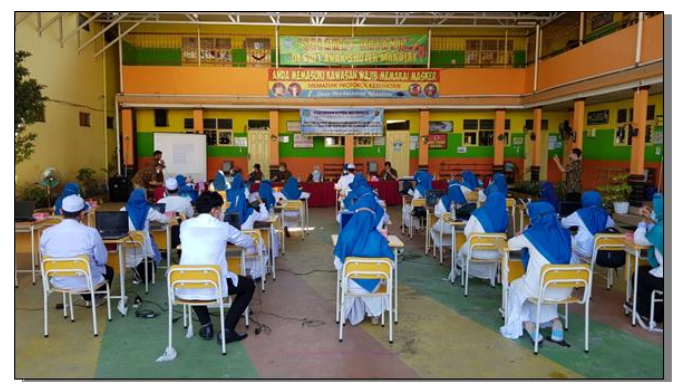

Gambar 3. Pelaksanaan kegiatan pengabdian

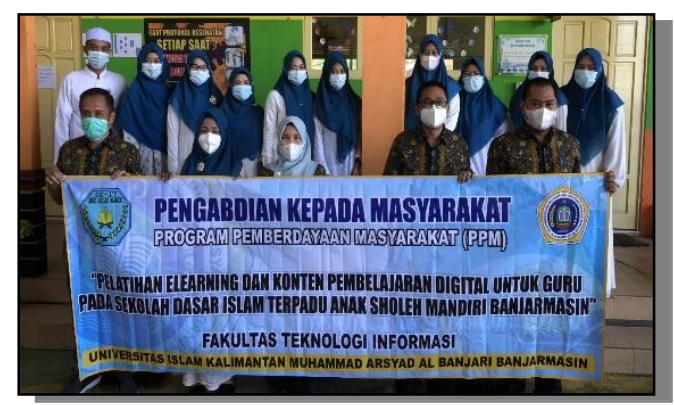

Gambar 5. Foto bersama setelah pengabdian selesai di depan SD IT Anak Sholeh Mandiri Banjarmasin

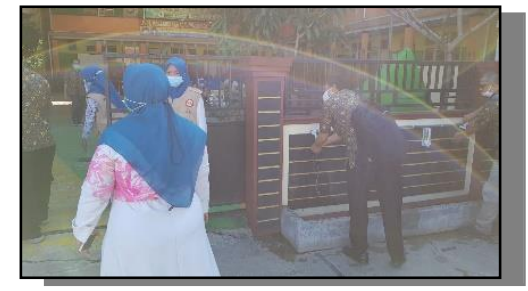

Gambar 6. Foto tetap menerapkan

Prokes selama kegiatan

\section{KESIMPULAN}

Setelah melaksanakan Pelatihan Elearning Dan Konten Pembelajaran Digital Untuk Guru Pada Sekolah Dasar Islam Terpadu Anak Sholeh Mandiri Banjarmasin dan berdasarkan hasil jawaban kuesioner maka dapat disimpulkan sebagai berikut:

1. Pelaksanaan Pengabdian Kepada Masyarakat Program Pemberdayaan Masyarakat (PPM) ini sangat berguna sekali bagi guru di SDIT Anak Sholeh Mandiri Banjarmasin karena selama pembelajaran daring (online) di masa pandemi ini ratarata guru kelas menggunakan media Whatsapp untuk proses pemberian materi, tugas, dan pengumpulan tugas yang memiliki kekurangan yaitu kadang data terhapus dan tertimpa oleh percakapan antar guru dan orang tua siswa.

2. Dengan pemberian materi Elearning Dan Konten Pembelajaran Digital guru sangat terbantukan karena 
pemberian materi, pengisian

kehadiran siswa, pemberian tugas, pengumpulan tugas dan penilaian semua terkelola dalam satu aplikasi dan data bisa di unduh kembali apabila diperlukan.

3. Kelebihan aplikasi Edmodo adalah guru dapat menggunakan handphone dalam penilaian dan pemantauan tugas siswa karena aplikasi ini sudah mendukung semua operation sistem yaitu Dekstop, Tablet maupun Handphone ditambah lagi fitur orang tua dapat memantau dari aplikasi apakah tugas anak sudah dikumpul atau dinilai oleh guru.

4. Hasil kuisioner yang telah dijawab oleh 27 responden bahwa setelah mereka menggunakan aplikasi Edmodo berdasarkan aspek manfaat penerapan IPTEK maka menghasilkan nilai rata-rata 4,8 artinya Sangat Setuju (SS).

5. Sedangkan dari aspek pemahaman dan keterampilan (Pendidikan) menghasilkan nilai rata-rata 4,9 artinya Sangat Setuju (SS).
6. Aplikasi Edmodo dapat diterapkan untuk mendukung proses belajar mengajar pada SD Islam Terpadu Anak Sholeh Mandiri dan memiliki banyak manfaat baik buat guru, siswa dan orang tua.

\section{DAFTAR PUSTAKA}

Ainiyah, Zamrotul. 2015. Penggunnan Edmodo sebagai Media Pembelajaran E-Learning Pada Mata Pelajaran Otomatisasi Perkantoran. Surabaya: UNESA.

Anonim $^{\mathrm{a}}$, 2010. office-2010, http://solutionanda.blogspot.com/2010/05/.htm l. Diakses pada hari Senin, 16 September 2019 pukul 21.00 WITA

Effendi dan Hartono Zhuang. 2005. Elearning Konsep dan Aplikasi. Yogyakarta: ANDI

Hidayat, Rahmat. 2010. Cara Praktis membangun website gratis. Jakarta: PT. Elex Madia Komputer.

Hidayatullah, Priyanto dan Jauhari Khairul Kawistara. 2014. Pemrograman Web. Bandung: Informatika.

Rudi, 2015, PerancanganAplikasi Sistem E-Learning Berbasis Web Di Smk Karya Pembangunan Jambe, Skripsi, STMIK Raharja, Tangerang 